\title{
Promoter Methylation Down-regulates Osteoprotegerin Expression in Ovarian Carcinoma
}

\author{
JI-YE KIM ${ }^{1,2}$, SE HOON KIM ${ }^{1}$ and HYUN-SOO KIM ${ }^{3}$ \\ ${ }^{1}$ Department of Pathology, Severance Hospital, Yonsei University College of Medicine, Seoul, Republic of Korea; \\ ${ }^{2}$ Department of Pathology, Ilsan Paik Hospital, Inje University College of Medicine, Goyang, Republic of Korea; \\ ${ }^{3}$ Department of Pathology and Translational Genomics, Samsung Medical Center, \\ Sungkyunkwan University School of Medicine, Seoul, Republic of Korea
}

\begin{abstract}
Background/Aim: Previous studies have documented that osteoprotegerin $(O P G)$ is involved in the development and progression of several human malignancies. However, OPG has also been shown to act as a tumor suppressor. The aim of this study was to examine the expression status of OPG in ovarian carcinoma cells and investigate the underlying mechanism responsible for alterations in OPG expression. Materials and Methods: The expression levels of OPG $\mathrm{mRNA}$ and protein were assessed in human ovarian carcinoma cell lines. The methylation status of the OPG promoter region was determined using the bisulfite pyrosequencing technique. The effects of demethylation on $O P G$ expression were also analyzed. Results: The human ovarian carcinoma cell lines, SW 626, OVCAR-3, ES-2, TOV-112D, and TOV-21G, expressed significantly lower levels of OPG $m R N A$ and protein than the normal human ovarian epithelial cell line, HS823.Tc. Moreover, three $\mathrm{Cp} G$ sites in the OPG promoter region were highly methylated in the SW 626, OVCAR-3, ES-2, and TOV$112 \mathrm{D}$ ovarian carcinoma cell lines compared to normal control cells. Furthermore, in all the examined ovarian carcinoma cell lines, treatment with the demethylating agent, 5-aza-2-deoxycytidine, resulted in significantly increased expression levels of OPG $m R N A$ and protein compared to the respective pre-treatment levels. Conclusion: OPG expression was down-regulated in the studied ovarian carcinoma cells compared to the normal control cells, while demethylation significantly restored OPG expression in the OPG-down-
\end{abstract}

Correspondence to: Dr. Hyun-Soo Kim, Department of Pathology and Translational Genomics, Samsung Medical Center, Sungkyunkwan University School of Medicine, 81, Irwon-ro, Gangnam-gu, Seoul 06351, Republic of Korea. Tel: +82 234101243, Fax:+82 234100025, e-mail: hyun-soo.kim@ samsung.com

Key Words: Ovarian carcinoma, osteoprotegerin, promoter methylation status. regulated cell lines. Our results suggest that OPG downregulation in ovarian carcinoma occurs, at least partly, through epigenetic repression, suggesting its involvement in ovarian carcinogenesis.

Ovarian carcinoma accounts for more than $90 \%$ of primary ovarian malignancies. It has the highest mortality rate of all gynecological tumors (1). Its high mortality is due to the lack of early detection methods and the high risk of recurrence. Most ovarian carcinoma cases are diagnosed at advanced stages, resulting in a five-year survival rate of approximately $47 \%(2,3)$. Moreover, the existing treatment of patients with ovarian carcinoma is limited to aggressive debulking surgery and postoperative adjuvant chemotherapy (1). Thereby, a thorough understanding of the alterations in gene expression that occur during ovarian carcinogenesis may aid in efforts to improve its diagnosis and treatment. A diagnostic or prognostic biomarker for ovarian carcinoma is urgently needed to guide the treatment of these patients.

Osteoprotegerin (OPG) is a secreted protein that belongs to tumor necrosis factor (TNF) receptor superfamily. In human tissues, a transcript of similar size is detected at highest levels in the lung, heart, kidney, and placenta, although there are detectable levels in various hematopoietic and immune organs (4). OPG acts as a decoy receptor for receptor activator of nuclear factor- $\varkappa \mathrm{B}$ ligand (RANKL) and TNF-related apoptosis-inducing ligand (TRAIL) (5). OPG has many biological functions; it was first described as a potent inhibitor of osteoclastic bone resorption (4). In addition to its role in bone metabolism, OPG is involved in the development, progression, and metastasis of several human malignancies (614). We have previously reported that OPG expression is down-regulated in primary colorectal carcinoma cells and tissues and that reduced OPG expression is significantly associated with aggressive oncogenic behavior and poor prognosis for colorectal carcinoma $(11,15)$. We have also demonstrated that the $O P G$ gene promoter is highly methylated in colorectal carcinoma cell lines and that 
treatment with a demethylating agent significantly elevates $O P G$ mRNA and protein expression (11).

There are a few previous studies that reported a possible association between OPG and apoptosis in ovarian carcinoma cells $(5,16)$. These studied documented that OPG attenuates TRAIL-induced apoptosis; however, its role in ovarian carcinogenesis is yet to be elucidated. Moreover, the expression of OPG and its precise regulatory mechanisms in ovarian carcinoma remain unclear. In this study, we investigated the expression levels of $O P G \mathrm{mRNA}$ and protein in ovarian carcinoma cells, as well as the methylation status of the $O P G$ promoter region. Moreover, the effects of demethylation on OPG expression were analyzed. Our results indicated that promoter methylation is one of the mechanisms that contribute to the down-regulation of OPG expression in ovarian carcinoma.

\section{Materials and Methods}

Cell culture and treatment. The Hs823.Tc human normal ovarian cell line as well as the SW 626, OVCAR-3, ES-2, TOV-112D, and TOV-21G ovarian carcinoma cell lines were purchased from the American Type Culture Collection (Manassas, VA, USA). The cells were maintained in Dulbecco's modified Eagle's medium or Roswell Park Memorial Institute 1640 medium supplemented with $10 \%$ heat-inactivated fetal bovine serum (FBS), penicillin (100 $\mathrm{U} / \mathrm{ml}$ ), and streptomycin $(100 \mu \mathrm{g} / \mathrm{ml}$ ) (all from Gibco, Life Technologies, Grand Island, NY, USA). All cell lines were treated as previously described $(1,11,17-19)$. The cells were cultured at $37^{\circ} \mathrm{C}$ in a humidified atmosphere of $5 \%$ carbon dioxide. The demethylating agent 5-aza-2-deoxycytidine (Sigma-Aldrich, St. Louis, MO, USA) was dissolved in phosphate-buffered saline to a concentration of $50 \mathrm{mg} / \mathrm{ml}$ as a stock solution and stored at $-20^{\circ} \mathrm{C}$ until use. Immediately before use, stock solutions were diluted in Roswell Park Memorial Institute 1640 medium without FBS. The cells were seeded in 6-well plates at a density of $5 \times 10^{5}$ cells $/ \mathrm{ml}$ in the media and treated with 5-aza-2-deoxycytidine (final concentration, $1 \mu \mathrm{M}$ ). The 5-aza-2-deoxycytidine was replaced with freshly prepared solution every $24 \mathrm{~h}$, and the cells were harvested $96 \mathrm{~h}$ after the initial treatment. Control cultures were treated under similar experimental conditions in the absence of 5-aza-2deoxycytidine (phosphate-buffered saline only).

Complementary DNA synthesis. Total RNA was isolated using TRI Reagent (Molecular Research Center, Cincinnati, OH, USA) according to the manufacturer's instructions. RNase-free DNase I (Thermo Fisher Scientific, Waltham, MA, USA) treatment was carried out to remove contaminating genomic DNA from the purified total RNA obtained from the cell lines. Isolated total RNA was diluted to $1 \mathrm{mg} / \mathrm{ml}$ with sterile diethylpyrocarbonate-treated water, and $2.5 \mathrm{ml}$ was added to reactions containing $1 \times$ DNase I buffer and $1 \mathrm{U}$ DNase I (final volume, $10 \mathrm{ml}$ ). After incubation at $37^{\circ} \mathrm{C}$ for $30 \mathrm{~min}$, the reactions were stopped by incubation at $70^{\circ} \mathrm{C}$ for $10 \mathrm{~min}$. DNase I-treated RNA was reverse-transcribed into firststrand cDNA using the ReverTra Ace qPCR RT kit (Toyobo, Osaka, Japan). One microgram of DNase I-treated RNA and $250 \mathrm{ng}$ of random primers were mixed in a $0.5-\mathrm{ml}$ PCR tube and brought to $11 \mathrm{ml}$ with sterile diethylpyrocarbonate-treated water, heated at $65^{\circ} \mathrm{C}$ for $5 \mathrm{~min}$, and chilled quickly on ice. Other reagents were added to the $20-\mathrm{ml}$ reaction volume at the following final concentrations: $1 \times$ First-Strand Buffer, $10 \mathrm{mM}$ dithiothreitol, 0.5 $\mathrm{mM}$ each dNTP, and $200 \mathrm{U}$ Superscript II Reverse Transcriptase (Invitrogen, Carlsbad, CA, USA). Reactions were incubated at $42^{\circ} \mathrm{C}$ for $1 \mathrm{~h}$ and heated to $70^{\circ} \mathrm{C}$ for $10 \mathrm{~min}$, and the products were stored at $-20^{\circ} \mathrm{C}$. The amount of cDNA was determined using NanoDrop ND-1000 spectrophotometer (Thermo Fisher Scientific).

Quantitative reverse transcription polymerase chain reaction ( $q R T$ $P C R)$. The cDNA was subjected to qRT-PCR analysis using the BioRad CFX96 Real-Time PCR Detection System (Bio-Rad Laboratories, Hercules, CA, USA). PCR was carried out in a $20-\mu 1$ reaction containing $0.5 \mu \mathrm{M}$ each primer, $1 \times$ Thunderbird SYBR qPCR Mix (Toyobo), and $2 \mu \mathrm{l}$ of template DNA. PCR for $O P G$ was performed on a C1000 Thermal Cycler (Bio-Rad Laboratories) using the following reaction protocol: polymerase activation at $95^{\circ} \mathrm{C}$ for $1 \mathrm{~min}$, followed by 40 cycles at $95^{\circ} \mathrm{C}$ for $10 \mathrm{~s}$ for denaturation, $58^{\circ} \mathrm{C}$ for $10 \mathrm{~s}$ for annealing, and $72^{\circ} \mathrm{C}$ for $20 \mathrm{~s}$ for extension. Amplification patterns were analyzed and threshold cycle numbers (Ct) for each sample were determined using CFX Manager Software (Bio-Rad Laboratories). The primer sequences used for $O P G$ were as follows: forward, 5'-TGC TGT TCC TAC AAA GTT TA-3', and reverse, 5'-CTT GAG TGC TTT AGT GCG T-3'. The $\Delta \Delta \mathrm{Ct}$ method was used to calculate relative $O P G$ expression after normalization to the expression of $\beta$-actin (20). Amplification of OPG was confirmed by melting-curve analysis, and target amplicon size (430 bp) by agarose gel electrophoresis (Thermo Fisher Scientific). Each sample was assayed in triplicate.

Enzyme-linked immunosorbent assay (ELISA). For analysis of OPG protein production, culture media were harvested and centrifuged to remove cellular debris. Media were concentrated by centrifugal filtration at 4,000 rpm for $20 \mathrm{~min}$ using the Amicon Ultra-10K concentrator (EMD Millipore, Burlington, MA, USA). A commercially available ELISA kit for Osteoprotegerin (Cloud-Clone Corporation, Katy, TX, USA) was used according to the protocols provided by the manufacturer to measure the concentrations of human OPG. Each sample was assayed in triplicate.

Genomic DNA extraction and bisulfite conversion. Genomic DNA was extracted from cultured cells using the NucleoSpin Tissue kit (Macherey-Nagel GmbH \& Co. KG, Duren, Germany) and quantified using a DropSense96 multichannel spectrophotometer (Trinean, Gentbrugge, Belgium). Bisulfite treatment was performed using the EZ DNA Methylation Kit (Zymo Research, Irvine, CA, USA) on 2 $\mu \mathrm{g}$ of DNA according to the protocols provided by the manufacturer.

Pyrosequencing. DNA methylation of $O P G$ was determined by bisulfite pyrosequencing. Primers were designed using Pyrosequencing Assay Design Software, Version 1.0.6 (Qiagen, Valencia, CA, USA). To ensure distinct pyrosequencing signals, the previously bisulfitemodified DNA (100 ng) was amplified by 45 cycles of PCR using the PyroMark PCR Kit (Qiagen) with a biotin-labeled primer according to the protocols provided by the manufacturer. The primer sequences used were as follows: forward, 5'-GGG TTT TGT AAT TTG AGG TTT TAG AA-3', and reverse, 5'-biotin-ACT TAT ATC TCC TCC ACC CTA AA-3'. PCR products were immobilized to Streptavidin Sepharose High-Performance (GE Healthcare, Chicago, IL, USA) beads via biotin affinity. PCR products were denatured to single- 
A

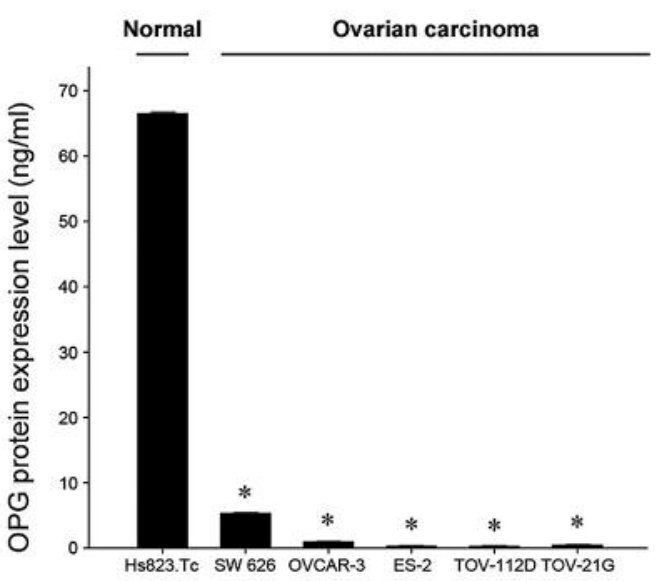

B

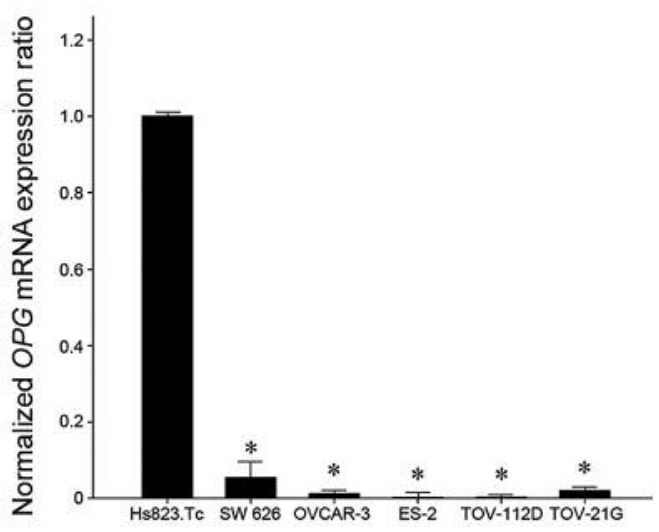

C

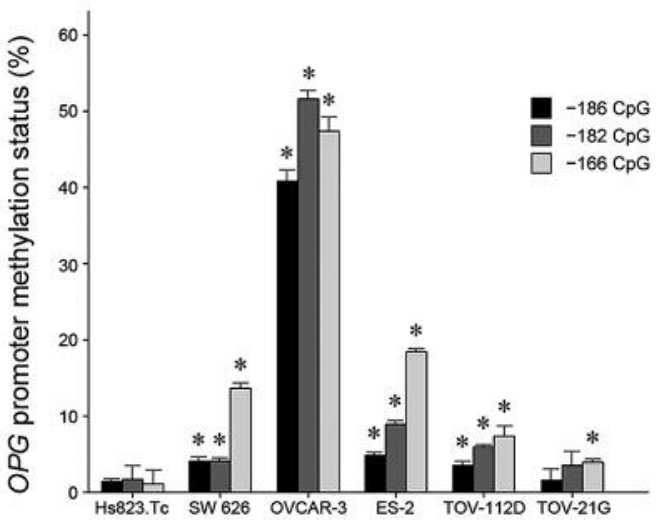

D

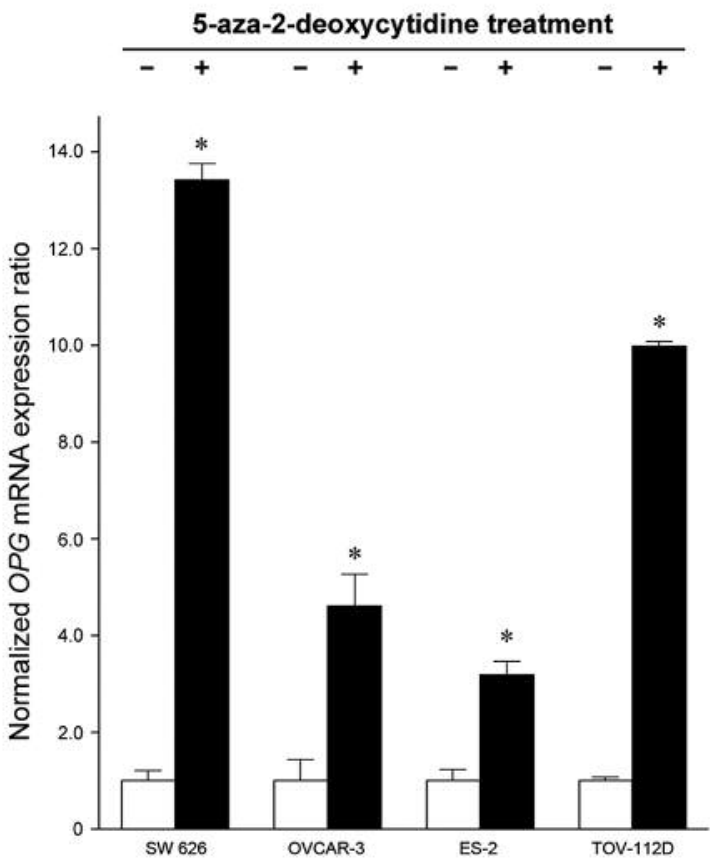

$\mathbf{E}$

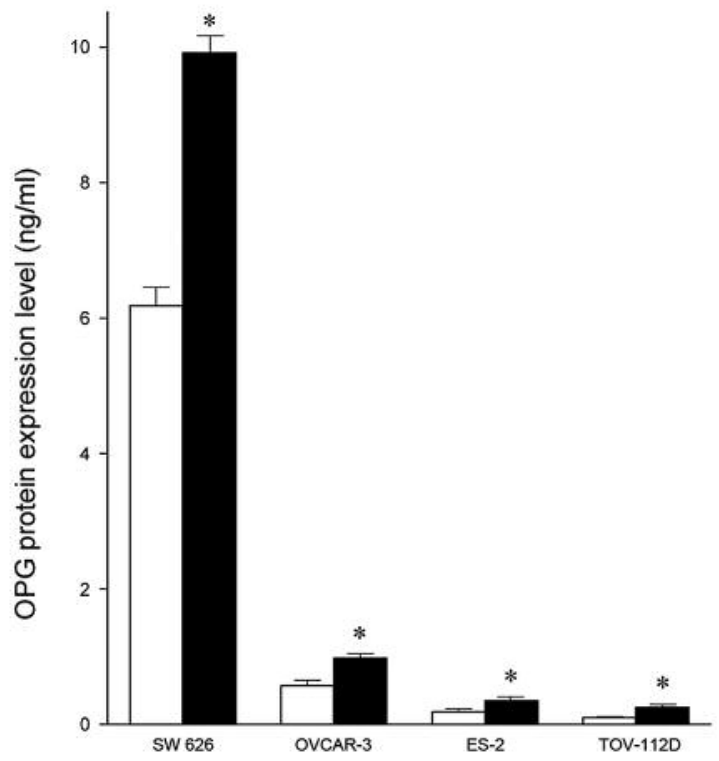

Figure 1. Expression of osteoprotegerin (OPG) in ovarian carcinoma and normal ovarian cell lines and effect of demethylation on OPG. (A) OPG protein expression levels measured by enzyme-linked immunosorbent assay. ${ }^{*} p<0.05$ versus Hs823.Tc cells (normal control). (B) Normalized OPG mRNA expression ratios measured by quantitative real-time reverse-transcriptase polymerase chain reaction. ${ }^{*} p<0.05$ versus $H s 823 . T c$ cells (normal control). (C) OPG promoter methylation status analyzed by bisulfite pyrosequencing. ${ }^{*} p<0.05$ versus Hs823.Tc cells (normal control). (D) Effect of 5-aza-deoxycytidine treatment on OPG mRNA expression. ${ }^{*} p<0.05$ versus pre-treatment level. (E) Effect of 5-aza-2-deoxycytidine treatment on $O P G$ protein expression. ${ }^{*} p<0.05$ versus pre-treatment level. Error bars represent the standard deviations.

stranded DNA and annealed with sequencing primers (5'-GAT AAA GGT TTG GGA TAT ATT-3'). Complexes of bead-bound singlestranded DNA and primer were applied to a PyroMark Q96 ID pyrosequencer (Qiagen) with PyroMark Gold Q96 Reagents (Qiagen).
Raw results were analyzed and visualized using Pyro Q-CpG Software, Version 1.0.0 (Qiagen). Pyrosequencing was performed for three independent bisulfite reactions, and the average methylation frequency for each $\mathrm{CpG}$ site was calculated. 
Table I. Osteoprotegerin $(O P G)$ mRNA and protein expression levels in ovarian carcinoma and control normal ovarian cell lines.

\begin{tabular}{|c|c|c|c|c|c|}
\hline \multirow[t]{2}{*}{ Cell line } & \multirow[t]{2}{*}{ Category } & \multicolumn{2}{|c|}{$O P G$ mRNA expression } & \multicolumn{2}{|c|}{ OPG protein level } \\
\hline & & Normalized ratio & $p$-Value & Mean \pm Standard deviation & $p$-Value \\
\hline Hs823.Tc & Normal & 1.000 & & $66.510 \pm 0.008$ & \\
\hline SW 626 & Carcinoma & 0.054 & $<0.001 *$ & $5.301 \pm 0.010$ & $<0.001 *$ \\
\hline OVCAR-3 & Carcinoma & 0.012 & $<0.001^{*}$ & $0.932 \pm 0.029$ & $<0.001 *$ \\
\hline ES-2 & Carcinoma & 0.002 & $<0.001 *$ & $0.283 \pm 0.014$ & $<0.001 *$ \\
\hline TOV-112D & Carcinoma & 0.003 & $<0.001 *$ & $0.230 \pm 0.008$ & $<0.001 *$ \\
\hline TOV-21G & Carcinoma & 0.020 & $<0.001 *$ & $0.472 \pm 0.003$ & $<0.001 *$ \\
\hline
\end{tabular}

*Statistically significant compared to control Hs823.Tc cells.

Table II. Osteoprotegerin $(O P G)$ promoter methylation status of three $C p G$ sites in ovarian carcinoma and control normal ovarian cell lines.

\begin{tabular}{|c|c|c|c|c|c|c|c|}
\hline \multirow[t]{2}{*}{ Cell line } & \multirow[t]{2}{*}{ Category } & \multicolumn{6}{|c|}{$O P G$ promoter methylation status $(\%)$} \\
\hline & & $-186 \mathrm{CpG}$ & $p$-Value & $-182 \mathrm{CpG}$ & $p$-Value & $-166 \mathrm{CpG}$ & $p$-Value \\
\hline Hs823.Tc & Normal & 1.44 & & 1.72 & & 1.11 & \\
\hline SW 626 & Carcinoma & 4.09 & $0.022 *$ & 4.10 & $0.029 *$ & 13.65 & $<0.001^{*}$ \\
\hline OVCAR-3 & Carcinoma & 40.83 & $<0.001^{*}$ & 51.61 & $<0.001 *$ & 47.40 & $<0.001 *$ \\
\hline ES-2 & Carcinoma & 4.86 & $0.017 *$ & 8.92 & $<0.001 *$ & 18.42 & $<0.001^{*}$ \\
\hline TOV-112D & Carcinoma & 3.53 & $0.036^{*}$ & 5.95 & $<0.001 *$ & 7.37 & $<0.001^{*}$ \\
\hline TOV-21G & Carcinoma & 1.59 & 0.211 & 3.54 & 0.077 & 3.95 & $0.045^{*}$ \\
\hline
\end{tabular}

*Statistically significant compared to control Hs823.Tc cells.

Statistical analysis. Data are expressed as mean \pm standard deviation of three independent experiments, each performed in triplicate, and are presented relative to control. Wilcoxon rank sum test was used to compare the promoter methylation frequency and the expression levels of $O P G$ mRNA and protein between the normal ovarian cell line and ovarian carcinoma cell lines. We used the Wilcoxon signedrank test to compare the expression levels of $O P G$ mRNA and protein before and after 5-aza-2-deoxycytidine treatment in each ovarian carcinoma cell line examined. Statistical analyses were performed using IBM SPSS Statistics for Windows, version 20 (IBM Corporation, Armonk, NY, USA). A $p$-value $<0.05$ was considered statistically significant.

\section{Results}

OPG expression in ovarian carcinoma cell lines. The ELISA results revealed that OPG protein expression was significantly reduced in SW $626(5.301 \pm 0.010 \mathrm{ng} / \mathrm{ml} ; p<0.001)$, OVCAR$3(0.932 \pm 0.029 \mathrm{ng} / \mathrm{ml} ; p<0.001), \mathrm{ES}-2(0.283 \pm 0.014 \mathrm{ng} / \mathrm{ml}$; $p<0.001)$, TOV-112D $(0.230 \pm 0.008 \mathrm{ng} / \mathrm{ml} ; p<0.001)$, and TOV-21G $(0.472 \pm 0.003 \mathrm{ng} / \mathrm{ml} ; p<0.001)$ cells compared to Hs823.Tc cells $(66.510 \pm 0.008 \mathrm{ng} / \mathrm{ml}$; Figure 1A). Consistent with these results, $O P G$ mRNA expression was significantly lower in SW 626 (normalized mRNA expression ratio, 0.054; $p<0.001)$, OVCAR-3 (0.012; $p<0.001)$, ES-2 (0.002; $p<0.001)$, TOV-112D $(0.003 ; p<0.001)$, and TOV-21G $(0.020$; $p<0.001)$ cells compared to the control Hs823.Tc cells (1.000; Figure 1B). Table I summarizes the expression levels of $O P G$ mRNA and protein in the examined ovarian carcinoma cells.

Mechanisms contributing to the down-regulation of OPG expression in ovarian carcinoma cell lines. We have previously observed that down-regulation of OPG expression is associated with promoter hypermethylation in colorectal carcinoma cells (11). Based on this observation, we hypothesized that promoter hypermethylation might explain the reduced OPG expression in ovarian carcinoma cells. We analyzed OPG promoter methylation status at three $\mathrm{CpG}$ sites $(-186 \mathrm{CpG},-182 \mathrm{CpG}$, and $-166 \mathrm{CpG})$ in the $O P G$ promoter region using a pyrosequencing technique. When compared to that in Hs823.Tc cells, $O P G$ promoter methylation was significantly increased in SW 62, OVCAR-3, ES-2, and TOV112D cells (Figure 1C), in all the examined CpG sites, indicating that promoter hypermethylation may be a possible mechanism for the reduced OPG expression in these cell lines. Table II summarizes the $O P G$ promoter methylation status and its differences between normal and carcinoma cell lines.

To further investigate the role of DNA methylation in the regulation of OPG expression, the ovarian carcinoma cell lines were treated with the demethylating agent 5-aza-2- 
deoxycytidine. Treatment resulted in significant restorations of $O P G$ mRNA expression, with a 13.419 -fold increase in SW 626 cells $(p<0.001)$, a 4.609-fold increase in OVCAR3 cells $(p<0.001)$, a 3.187 -fold increase in ES-2 cells $(p=0.002)$, and a 9.980 -fold increase in TOV-112D cells $(p<0.001)$ compared to the respective pre-treatment levels (Figure 1D). The restorative effect of 5-aza-2-deoxycytidine on OPG expression in these cell lines was also confirmed by ELISA (Figure 1E). When compared to the respective pretreatment OPG protein levels, the post-treatment levels were significantly elevated in SW $626(6.183 \pm 0.096 \mathrm{ng} / \mathrm{ml}$ to $9.921 \pm 0.033 \mathrm{ng} / \mathrm{ml} ; p<0.001)$, OVCAR-3 $(0.570 \pm 0.001$ $\mathrm{ng} / \mathrm{ml} 0.982 \pm 0.002 \mathrm{ng} / \mathrm{ml} ; p<0.001)$, ES-2 $(0.184 \pm 0.016$ $\mathrm{ng} / \mathrm{ml} \quad 0.348 \pm 0.006 \mathrm{ng} / \mathrm{ml} ; p<0.001)$, and TOV-112D $(0.101 \pm 0.032 \mathrm{ng} / \mathrm{ml} 0.252 \pm 0.029 \mathrm{ng} / \mathrm{ml} ; p=0.003)$ cells (Figure 1E). These findings suggest that promoter methylation affects OPG expression in ovarian carcinoma cell lines.

\section{Discussion}

In this study, we analyzed the expression of $O P G$ mRNA and protein in human ovarian carcinoma cells. We observed that all the examined ovarian carcinoma cell lines exhibited significantly lower $O P G$ mRNA expression levels than the normal ovarian cell line. Consistent with this result, OPG protein expression was significantly reduced in ovarian carcinoma cell lines. Our observations indicate that OPG expression is down-regulated in ovarian carcinoma, suggesting that it may serve as a potential diagnostic biomarker for ovarian carcinoma.

We also investigated the regulatory mechanisms for OPG expression. A possible mechanism by which OPG is downregulated in ovarian carcinoma cells is inhibition of gene expression by promoter hypermethylation. First, increased promoter methylation status was confirmed in SW626, OVCAR-3, ES-2, and TOV-112D cells via OPG promoter region ( $\mathrm{CpG}$ site) bisulfite pyrosequencing. Then, treatment with a demethylating agent significantly restored OPG mRNA and protein expression in all examined ovarian carcinoma cell lines, which had very low pre-treatment mRNA and protein levels. These findings suggest that promoter hypermethylation plays a critical role in OPG down-regulation in ovarian carcinoma cells. Our results are in agreement with our previous in vitro studies on colorectal carcinoma (11), in which $O P G$ mRNA and protein levels were significantly reduced among colorectal carcinoma cells compared to normal colonic epithelial cells. OPG downregulation in colorectal carcinoma was found to be a result of hypermethylation in the promoter region. Similar to our findings, Lu et al. also demonstrated that nasopharyngeal (NPC-TW04) and colorectal (HCT 116) carcinoma cell lines were highly methylated at the upstream or downstream of
$O P G$ transcription start site compared to normal nasal epithelial cells (12). Moreover, they observed a uniform reduction in OPG expression levels across a wide spectrum of human malignancies such as carcinomas of the oral cavity, nasopharynx, cervix, lungs, breast, pancreas, kidneys, prostate, and liver (12). Furthermore, Delgado et al. revealed that in the HEK-293 human embryonic kidney cell line, $\mathrm{CpG}$ islands of the $O P G$ promoter were hypermethylated, resulting in a significant decrease in $O P G$ mRNA expression levels (21). They also documented that treatment with a demethylating agent promoted a 20 -fold induction of $O P G$ mRNA expression in HEK-293 cells. Taken together, these results support our findings that promoter hypermethylation is a likely mechanism by which OPG is down-regulated.

However, our observations of OPG down-regulation conflict with previous reports in other malignancies showing that OPG exerts tumor-promoting effects. Analysis of the Cancer Genome Atlas (https://cancergenome.nih.gov/) dataset for lung carcinoma revealed a significant increase in OPG expression in lung carcinoma tissues compared to that in normal lung tissues (22). Prostate carcinoma cells were found to produce OPG in vitro and protect themselves against TRAIL-induced apoptosis (10). In the same context, an in vivo study demonstrated that OPG administration significantly decreased the growth of prostate carcinoma xenografts in nude mice (23). Furthermore, in osteosarcoma and lung carcinoma cell lines OPG overexpression was associated with aggressive oncogenic behavior such as increased cellular proliferation, migration, and invasion $(22,24)$. In contrast, studies on breast carcinoma using publicly available microarray data showed that OPG expression was associated with a better prognosis for patients with estrogen receptor-positive breast carcinoma (25). We have previously demonstrated that reduced OPG expression is significantly associated with aggressive oncogenic behavior in primary colorectal carcinoma and that OPG expression is an independent predictor of recurrent hepatic metastasis and independent prognostic factor for worse survival rates $(11,15)$. These conflicting data regarding the role of OPG may be related to the differences in organs and cell types, as well as the inadequacy of using a single model to explain the complex process of carcinogenesis.

In conclusion, we demonstrated that OPG expression was significantly down-regulated in ovarian carcinoma cells compared to normal ovarian cells, suggesting that it may serve as a potential diagnostic biomarker for ovarian carcinoma. Moreover, the three studied $\mathrm{CpG}$ sites of the $O P G$ promoter were highly methylated, and treatment with a demethylating agent significantly restored OPG expression in all the examined ovarian carcinoma cell lines. Our data strongly suggest that methylation-dependent 
mechanisms influence the transcription of the $O P G$ gene. This study is the first to explore the expression status of OPG in ovarian carcinoma cell lines and to show that promoter hypermethylation is one of the mechanisms involved in the regulation of OPG expression. Further studies on the role of OPG in ovarian carcinoma could reveal important evidence regarding its potential use as a therapeutic target.

\section{Authors' Contributions}

All Authors were responsible for substantial contributions to the conception and design of the study, acquisition, analysis, and interpretation of the data, as well as drafting the manuscript, revising the manuscript critically for important intellectual content, and providing final approval of the version to be published.

\section{Conflicts of Interest}

None of the Authors have any conflicts of interest to declare regarding this study.

\section{Acknowledgements}

This research was supported by the Basic Science Research Program through the National Research Foundation of Korea (NRF) funded by the Ministry of Education (2016R1D1A1B03935584).

\section{References}

1 Kim JY, Do SI, Bae GE and Kim HS: B-cell translocation gene 1 is downregulated by promoter methylation in ovarian carcinoma. J Cancer 8: 2669-2675, 2017. PMID: 28928854. DOI: $10.7150 /$ jca. 21037

2 Bandera CA: Advances in the understanding of risk factors for ovarian cancer. J Reprod Med 50: 399-406, 2005. PMID: 16050564.

3 Piek JM, van Diest PJ and Verheijen RH: Ovarian carcinogenesis: an alternative hypothesis. Adv Exp Med Biol 622: 79-87, 2008. PMID: 18546620. DOI: 10.1007/978-0-38768969-2_7

4 Simonet WS, Lacey DL, Dunstan CR, Kelley M, Chang MS, Luthy R, Nguyen HQ, Wooden S, Bennett L, Boone $T$, Shimamoto G, DeRose M, Elliott R, Colombero A, Tan HL, Trail G, Sullivan J, Davy E, Bucay N, Renshaw-Gegg L, Hughes TM, Hill D, Pattison W, Campbell P, Sander S, Van G, Tarpley J, Derby P, Lee R and Boyle WJ: Osteoprotegerin: a novel secreted protein involved in the regulation of bone density. Cell 89: 309319, 1997. PMID: 9108485.

5 Lane D, Matte I, Rancourt C and Piche A: Osteoprotegerin (OPG) protects ovarian cancer cells from TRAIL-induced apoptosis but does not contribute to malignant ascites-mediated attenuation of TRAIL-induced apoptosis. J Ovarian Res 5: 34, 2012. PMID: 23153223. DOI: $10.1186 / 1757-2215-5-34$

6 Brown JM, Corey E, Lee ZD, True LD, Yun TJ, Tondravi M and Vessella RL: Osteoprotegerin and RANK ligand expression in prostate cancer. Urology 57: 611-616, 2001. PMID: 11306358. DOI: S0090-4295(00)01122-5
7 Brown JM, Vessella RL, Kostenuik PJ, Dunstan CR, Lange PH and Corey E: Serum osteoprotegerin levels are increased in patients with advanced prostate cancer. Clin Cancer Res 7: 29772983, 2001. PMID: 11595685.

8 De Toni EN, Thieme SE, Herbst A, Behrens A, Stieber P, Jung A, Blum H, Goke B and Kolligs FT: OPG is regulated by betacatenin and mediates resistance to TRAIL-induced apoptosis in colon cancer. Clin Cancer Res 14: 4713-4718, 2008. PMID: 18676739. DOI: 10.1158/1078-0432.CCR-07-5019

9 Holen I, Cross SS, Neville-Webbe HL, Cross NA, Balasubramanian SP, Croucher PI, Evans CA, Lippitt JM, Coleman RE and Eaton CL: Osteoprotegerin (OPG) expression by breast cancer cells in vitro and breast tumours in vivo: A role in tumour cell survival? Breast Cancer Res Treat 92: 207-215, 2005. PMID: 16155791. DOI: 10.1007/s 10549-005-2419-8

10 Holen I, Croucher PI, Hamdy FC and Eaton CL: Osteoprotegerin (OPG) is a survival factor for human prostate cancer cells. Cancer Res 62: 1619-1623, 2002. PMID: 11912131.

$11 \mathrm{Kim}$ HS, Yoon G, Do SI, Kim SJ and Kim YW: Downregulation of osteoprotegerin expression as a novel biomarker for colorectal carcinoma. Oncotarget 7: 15187-15199, 2016. PMID: 26942563. DOI: 10.18632/oncotarget.7885

12 Lu TY, Kao CF, Lin CT, Huang DY, Chiu CY, Huang YS and Wu HC: DNA methylation and histone modification regulate silencing of OPG during tumor progression. J Cell Biochem 108: 315-325, 2009. PMID: 19565568. DOI: 10.1002/jcb.22256

13 Pettersen I, Bakkelund W, Smedsrod B and Sveinbjornsson B: Osteoprotegerin is expressed in colon carcinoma cells. Anticancer Res 25: 3809-3816, 2005. PMID: 16309167.

14 Tsukamoto S, Ishikawa T, Iida S, Ishiguro M, Mogushi K, Mizushima H, Uetake H, Tanaka H and Sugihara K: Clinical significance of osteoprotegerin expression in human colorectal cancer. Clin Cancer Res 17: 2444-2450, 2011. PMID: 21270110. DOI: $10.1158 / 1078-0432 . C C R-10-2884$

15 Moon A, Do SI, Kim HS and Kim YW: Downregulation of osteoprotegerin expression in metastatic colorectal carcinoma predicts recurrent metastasis and poor prognosis. Oncotarget 7: 79319-79326, 2016. PMID: 27764814. DOI: 10.18632/ oncotarget.12686

16 Lane D, Matte I, Laplante C, Garde-Granger P, Rancourt C and Piche A: Osteoprotegerin (OPG) activates integrin, focal adhesion kinase (FAK), and Akt signaling in ovarian cancer cells to attenuate TRAIL-induced apoptosis. J Ovarian Res 6: 82, 2013. PMID: 24267510. DOI: 10.1186/1757-2215-6-82

17 Joo JW, Kim HS, Do SI and Sung JY: Expression of zinc finger and BTB domain-containing 7A in colorectal carcinoma. Anticancer Res 38: 2787-2792, 2018. PMID: 29715100. DOI: 10.21873/anticanres.12522

18 Jung YY, Sung JY, Kim JY and Kim HS: Down-regulation of Bcell translocation gene 1 by promoter methylation in colorectal carcinoma. Anticancer Res 38: 691-697, 2018. PMID: 29374692. DOI: 10.21873 /anticanres.12274

19 Sung JY, Na K and Kim HS: Down-regulation of inositol polyphosphate 4-phosphatase type ii expression in colorectal carcinoma. Anticancer Res 37: 5525-5531, 2017. PMID: 28982866. DOI: 10.21873 /anticanres.11984

20 Livak KJ and Schmittgen TD: Analysis of relative gene expression data using real-time quantitative PCR and the $2-\Delta \Delta \mathrm{Ct}$ Method. Methods 25: 402-408, 2001. PMID: 11846609. DOI: 10.1006/meth.2001.1262 
21 Delgado-Calle J, Sanudo C, Fernandez AF, Garcia-Renedo R, Fraga MF and Riancho JA: Role of DNA methylation in the regulation of the RANKL-OPG system in human bone. Epigenetics 7: 83-91, 2012. PMID: 22207352. DOI: 10.4161/epi.7.1.18753

22 Yu Z, Sanders AJ, Owen S, Cheng S, Yang X and Jiang WG: Expression of osteoprotegrin is enhanced in lung cancer tissues and promotes aggressive cellular traits in H3122 lung cancer cells. Anticancer Res 37: 4277-4283, 2017. PMID: 28739719. DOI: 10.21873/anticanres.11820

23 Kiefer JA, Vessella RL, Quinn JE, Odman AM, Zhang J, Keller ET, Kostenuik PJ, Dunstan CR and Corey E: The effect of osteoprotegerin administration on the intra-tibial growth of the osteoblastic LuCaP 23.1 prostate cancer xenograft. Clin Exp Metastasis 21: 381-387, 2004. PMID: 15672862.
24 Marley K, Bracha S and Seguin B: Osteoprotegerin activates osteosarcoma cells that co-express RANK and RANKL. Exp Cell Res 338: 32-38, 2015. PMID: 26254896. DOI: 10.1016/ j.yexcr.2015.08.001

25 Sanger N, Ruckhaberle E, Bianchini G, Heinrich T, MildeLangosch K, Muller V, Rody A, Solomayer EF, Fehm T, Holtrich U, Becker S and Karn T: OPG and PgR show similar cohort specific effects as prognostic factors in ER positive breast cancer. Mol Oncol 8: 1196-1207, 2014. PMID: 24785095. DOI: 10.1016/j.molonc.2014.04.003

Received February 19, 2019 Revised March 28, 2019 Accepted April 2, 2019 